\title{
Experiment analysis on the characteristic of empty fruit bunch, palm kernel shell, coconut shell, and rice husk for biomass boiler fuel
}

\author{
Sivabalan Kaniapan ${ }^{1,2}$, H. Suhaimi ${ }^{1}$, Y. Hamdan ${ }^{1}$ and Jagadeesh Pasupuleti² \\ ${ }^{1}$ Mechanical Engineering Department, Universiti Teknologi PETRONAS, 32610 Seri Iskandar, Perak, Malaysia \\ Phone: +6053688000; Fax: +6053654082 \\ 2 Faculty of Engineering, University Tenaga Nasional, 43000 Kajang, Selangor, Malaysia
}

\begin{abstract}
It has been a necessary option for most developing countries moving towards renewable energy options as part of the Paris Agreement, which minimizes conventional energy sources' reliance. In Malaysia, biomass is a profitable renewable option compared to solar and hydro sources for energy production due to the abundance of agricultural biomass availability for immediate use. However, most of the biomass power plants in Malaysia depend on empty fruit bunch as fuel, causing problems when there is a shortage of fuel supply and other circumstances. Variations in the fuels' properties provide a new challenge to the power plant output; however, mixing biomass fuels can overcome the issue. Hence, this article aims to study the empty fruit bunch (EFB) with other abundant biomass fuels like "palm kernel shell (PKS)," "rice husk (RH)," and "coconut shell (CS)" for biomass boiler fuel. Therefore, the biomass's composition and characteristics need to be known, which was done through the proximate analysis $(P A)$, ultimate analysis (UA), and high heating value (HHV). As a result of PA, UA, and HHV, RH is the least favourable fuel due to lowest ((moisture $(4.92 \%)$, volatile matter $(63.20 \%)$, carbon $(42.50 \%)$, hydrogen $(5.42 \%)$, nitrogen $(0.43 \%)$ and sulphur $(0.01 \%)$ ) and highest ash content $(18.19 \%)$, whereas CS exhibits the most favourable option with highest (carbon $(50.25 \%)$ and oxygen $(42.57 \%)$ ) and second highest in HHV (20.53\%) compared with PKS. Thus, the experiments have provided the least and highest favourable feedstock ratios option for biomass boiler fuel application.
\end{abstract}

\section{ARTICLE HISTORY}

Received: $18^{\text {th }}$ Jan 2021

Revised: 23rd July 2021

Accepted: $10^{\text {th }}$ Aug 2021

\section{KEYWORDS}

Renewable energy; proximate analysis; ultimate analysis; low bulk density; biomass chemical characterization.

\section{INTRODUCTION}

Increasing awareness of the sustainable environmental values has made it acceptable that conventional fossil fuel dependence causes high environmental impacts resulted in greenhouse gas emission issues (GHG), carbon dioxide $\left(\mathrm{CO}_{2}\right)$ emissions, and environmental pollution [1]. Developing countries such as Malaysia, India, China, and others rely heavily on the rapidly depleting fossil fuels in today's world energy summary. At current development rates, global proven natural gas and petroleum fuel reserves are expected to supply for about 60.3 and 41.8 years, respectively [2]. Consequently, renewable energy plays the role of clean and green energy in providing feasible energy resources as an effective solution for fossil fuel extinction [3].

Electricity is one of the fundamental and core forms of energy. It is one of the quickest developing mediums on the planet where the use of electricity is the way to economic development and raises living standards among people. "International Energy Agency (IEA)" evaluated the global energy utilization will shoot up by 53\% in the year 2030 . In the year $2017,77.5 \%$ of fossil fuel has been utilized, which increased by $13.9 \%$ compared with the year 2012, whereby only $68 \%$ of the world's electricity generation depended essentially on petroleum derivatives, as per the IEA [4]. These energy sources, incorporate $25.9 \%$ coal, $21.2 \%$ natural gas, and $30.4 \%$ oil, and the rest comprises of $22.6 \%$ collectively as in biofuels \& waste, hydropower, nuclear power and others, such as "wind, solar PV, solar thermal, and geothermal" which has been shown separately in the below Figure 1 [4]. These mentioned figures are proof of dependency on fossil sources that arise from day to day as the electricity demand increases, particularly in developing nations.

Besides that, electricity generated by using fossil fuels leads to adverse environmental impacts due to $\mathrm{CO}_{2}$ emissions, greenhouse effects, global warming, and human health deterioration contributing to skin cancer, diseases related to the respiratory system, and others [5, 6]. Even though the production of energy based on fossil fuels is much cheaper than renewable energy options, petroleum fuels are less effective in the long run due to resource-constrained [7]. Other than that, population growth that causes the urging of energy needs increases and has become a vital factor in elevating global consumption of energy [8]. Clean energy resources such as biomass are, therefore, crucial in ensuring a sustainable supply of electricity and in preserving the world for future generations.

Several countries have been actively correlated with biomass utilization as a renewable option, where the use of biomass as an alternative energy solution has become an emerging worldwide trend [9]. Malaysia is not sauntered in combating the adverse effect of fossil fuel usage in comparison with other countries globally. It can be sustainable energy 
production or addressing the issue of environmental impacts; Malaysia has opened up a new platform by going in-depth to the core of the problems via several new government legislation and policies introduction such as "Five-Fuel Policy 2001, National Green Technology Policy 2009 (NGT), National Renewable Energy Policies (NRE)" and subsidies in various form such as" feed-in tariffs," tax incentive in both tax allowances and exemption of tax for future RE projects.

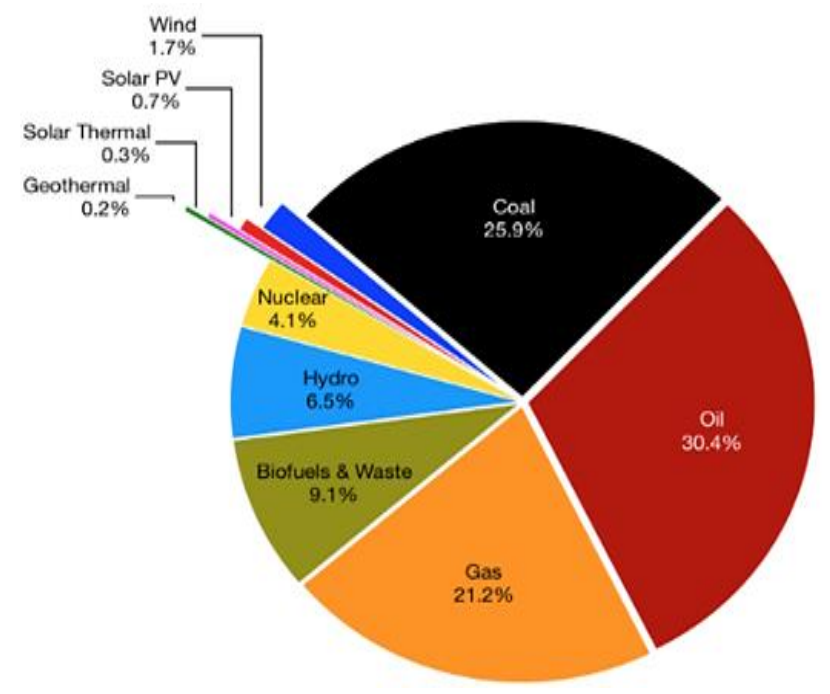

Figure 1. Illustrated prime world energy categories in the year 2017 based on calculated IEA report year 2019 [4]

\section{Malaysia's Biomass Power Plant and Potential Agricultural Residues which can be used as Fuel}

In exploring the expedition of fuel resources, biomass have been identified. Biomass is a degradable living organism of a certain amount of waste, products, and residues from agriculture, forestry, and industrial and household waste [10]. It refers to plant-derived organic matter, which is produced through photosynthesis [11]. Biomass is an alternative energy that can contribute to the primary energy mixture, which is cleaner and does not emit gaseous pollutants and as a replacement for finite sources such as fossil forms which can be used in such as burning in the material's free state, burning of the compressed material in pellets and briquettes form, and burning by pyrolysis and biogas combustion.

Developing renewable energy technology to turn natural resources into energy in recent years is now widely recognized as a critical component in delivering an integrated solution to deplete fossil fuels and minimize emissions. Also, renewable energy is an obvious option for ensuring continuous power supply and indirectly halting greenhouse gas emission. Many developing countries are now pursuing infinite and recurrent surrogate energy solutions such as biomass, wind, wave, solar, and hydrokinetic [12]. It is undeniable that Malaysia has allocated a few power plant projects to find the solution towards replacing the fossil fuel usage where it has reached a peak level in today's millennial. Energy-based projects have been implemented in recent years by the Malaysian government, as shown in Table 1 [13] below, to deploy energy security and concurrently suppress $40 \%$ of $\mathrm{CO}_{2}$ emission by 2020 compared to the emission severity in the year 2005 [14]. These biomass power plants are using a single source of fuel, and the reliability of this fuel source is quite uncertain shortly of its availability. Thus, fuel source diversification is necessary to tackle the issues of dependency on a single biomass source.

As among the nations with dynamic agricultural activities and among the second biggest in the oil palm industry, Malaysia has conventional energy assets like oil and gas and other inexhaustible options such as biomass, solar, and hydro energy resources. Nevertheless, the biomass resource potential of energy production is yet to be appropriately used in the region.

Table 1. Illustrated a few biomass power plants in Malaysia [13]

\begin{tabular}{lllll}
\hline Plant Owner & Location & Capacity $(\mathrm{MW})$ & Technology & Fuel \\
\hline Maju Intan Biomass & Perak & 12.5 & Steam turbine & Palm waste \\
Jana Landfill & Selangor & 2.0 & Gas turbine & Biogas \\
Naluri Ventures & Johor & 12 & Steam turbine & Palm waste \\
Bentong Biomass Energy & Pahang & 14 & Steam turbine & Palm waste/ wood \\
Kina biopower & Sabah & 11.5 & Steam turbine & Palm waste \\
\hline
\end{tabular}


According to Salman Zafar [15], the prime agrarian crops' in Malaysia are "coconut (6.34\%), cocoa (6.75\%), rice (12.68\%), oil palm (34.56\%), and rubber (39.67\%)" as appeared in Figure 2. Griffin et al. [16] have discovered that Malaysia delivers a total of 17 million tons of biomass waste per annum, whereby the palm oil waste typically represents $77 \%$ of biomass feedstock. Griffin et al. [16] and Nurhidayati et al. [17] has found that waste from palm oil incorporates the "palm kernel shell (PKS) and empty fruit bunch (EFB), while the rest are from agricultural and forestry by-products, such as forest residues $(8.2 \%)$, rice residues (9.1\%) consisting of (rice straw (RS) and rice husk (RH)), and (5.7\%) of other residues, for example, rubber, cocoa and coconut shell (CS)" as shown in Figure 3.

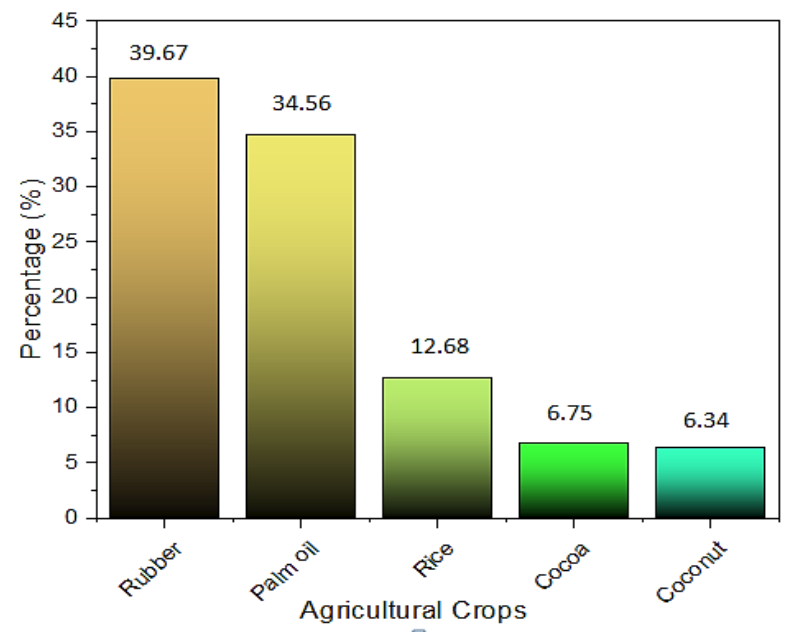

Figure 2. The prime agrarian crops grown in Malaysia [15]

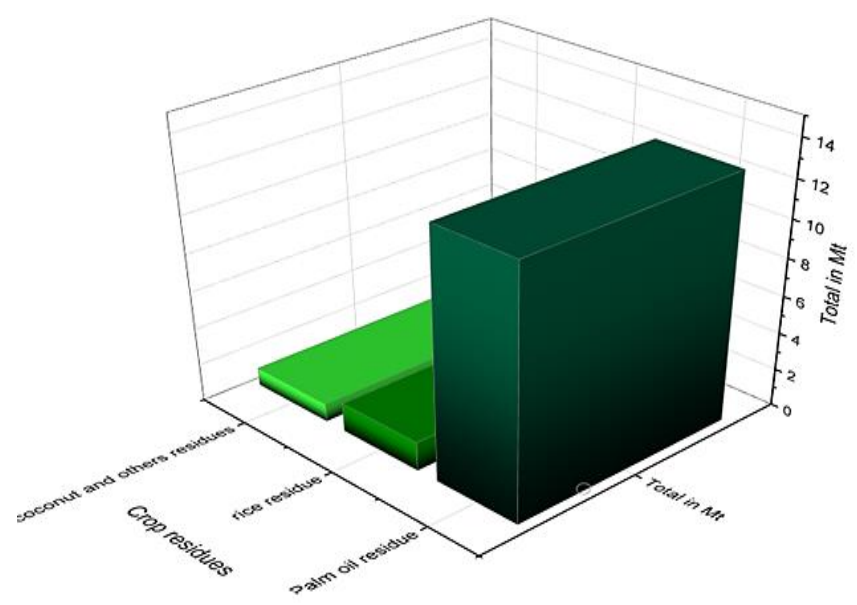

Figure 3. Palm oil residues, rice residues, and coconut residues in Malaysia [16, 17]

\section{Types of Biomass}

With the aid of a specific chemical, biological, and physical processes, the biodegradable feedstock is feasibly altered into solid, liquid, and gaseous fuels [18]. Biomass conversion aims specifically at turning a solid carbonaceous material into "fuels with physio-chemical characteristics that enable economic repository and transmutability through pumping systems," which has initially been challenging to manage due to voluminous and low-energy. Biomass can be presented in three primary forms of matter which are solid (bark and wood, residues from lumber mills, and sawdust) [19], liquid (animal fat, plants, and vegetable oils) [20], and gaseous such as "methane $\left(\mathrm{CH}_{4}\right)$ " and "carbon dioxide $\left(\mathrm{CO}_{2}\right)$ " and smaller fraction of "hydrogen sulfide $\left(\mathrm{H}_{2} \mathrm{~S}\right)$ " and other products $[21,22]$ produced via anaerobic digestion. These necessary forms of biomasses can be subdivided into "primary" and "secondary" products through the photosynthesis reaction by using direct sunlight and decomposition or conversion of biological feedstock, respectively [23].

In this paper, solid biomass from agricultural waste, particularly on the palm oil residues, rice mill residue, and coconut residue, has been chosen to be the topic of discussion due to the abundance available in the region of Malaysia. In the sense of using these above-mentioned biodegradable materials feedstocks in the boiler for energy production, the study of its composition of these agricultural residues is very crucial. In the upcoming section, both the composition and physiochemical properties of these "palm oil" derivatives such as "palm kernel shell (PKS), empty fruit bunch (EFB)," and rice husk (RH) from rice mill residues, and coconut shell (CS) has been discussed in details for a complete understanding of the fuels. 


\section{Composition of Biomass}

"Hemicellulose, cellulose, and lignin" are three supreme elements of biomass together with specific minerals, and extractives make up around $90 \%$ of the total material [24]. In the developing processes, the development of fuel derivatives and chemicals, the chemical composition, and fundamental organic components of biomass are significant [25]. Their polymer structure, length, and cross-linkage differ significantly during gasification and pyrolysis, resulting in different characteristics and thermal decomposition products. Understanding the impact of "hemicellulose, cellulose, and lignin" lie "on the thermal biomass breakdown," and by-products are essential factors for flexible biorefineries [26].

Cellulose exists in assorted types, and a substantial amount comes from industrial and domestic waste is an enormous component of wood and plant. Mohan, Pittman, and Steele [27] have experimented and found that the wood strength is provided by cellulose fibres and reflects the dry wood with around (40-50) \% weight. Few lignocellulosic substances consist of extra cellulose compared to wood. Cellulose is a special "pure organic polymer" comprises only units of "anhydroglocose" kept as one in a massive straight-chain molecule [28]. By disassembling the biomass's lignocellulosic, cellulose from lignin and hemicellulose can be extracted to generate the desired biofuel. Other than that, the cellulose macromolecules' depolymerization greatly enhances the biological and chemical conversion of cellulose to biofuel. The depolymerized cellulose, which is glucose, should then transform into biofuel via biological treatments, and the final product is then purified biofuel [29].

The next central chemical part of the wood is hemicelluloses, commonly referred to as polyose. Balat et al. [28] and Mohan et al. [27] have identified several hemicelluloses typically comprise (25-35\%) of the dry wood mass, $28 \%$ of the softwood mass, and $35 \%$ of the hardwood mass. Also, hemicelluloses are variable-composition polysaccharides, including five and six units of carbon monosaccharides [30] and branched, containing side pendants which constitute its non-crystalline nature. Tarasov, Leitch, and Fatehi [31] have proved that hemicelluloses are also easily hydrolyzed in acids, hydrophilic, and soluble in alkaline. Seed coats, or bran's, from commercially processed seeds such as corn, wheat, oats, barley, rice, and soybeans are the best commercial source of hemicelluloses.

"Lignin is an aromatic polymer which is synthesized by phenylpropanoid precursors" [32]. Balat et al. [28] have proven from their study that, in general, the presence of lignin is higher in softwood compared with hardwoods. Balat further added [33] that in softwoods and hardwoods, the content of dry lignin usually varies from (20-40) \% and (10 40) $\%$ by weight depends on the various herbaceous species. The lignin is an unnatural phenylpropane polymer. The lignocellulosic components heavily affect the percentages of monomer units that are quite complex. The rearrangement reaction of the volatile compound is usually low weight gasses that are often incondensable. To this end, it is recommended that high lignin content biomass to be used to produce solid fuel which could replace coal in industrial uses [15].

\section{METHODOLOGY}

\section{Biomass Feedstock Preparation}

Overall, a brief methodology schematic has been well presented in Figure 4, whereby all biomass samples such as "(EFB), (PKS), (RH), and (CS)," are readily available in most of the Asian countries, mainly Malaysia. Both "EFB and PKS" were procured from a "palm oil plantation," while CS was obtained from local producers selling coconut milk, whereas a rice corporation in Malaysia supplied RH. After receiving all four samples, the samples were left to dry in an oven at $105{ }^{\circ} \mathrm{C}$ for 24 hours to remove moisture from any available content. After all four samples were dehydrated, the biomass samples were then ground using a mortar grinder and biomass grinder into powder form, and next were sieved into sizing $0.30<\mathrm{dp} 1<0.50 \mathrm{~mm}$. Lastly, to avoid moisture absorption, the biomass samples were kept in airtight containers, as shown in Figure 5 below.

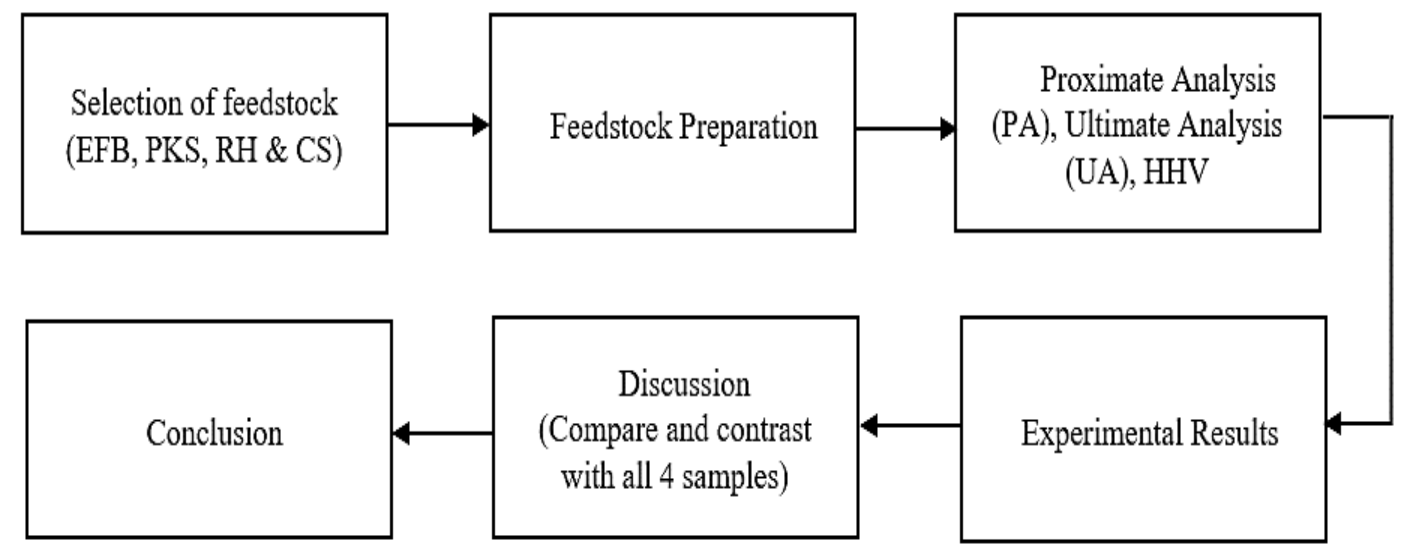

Figure 4. Methodology presentation 

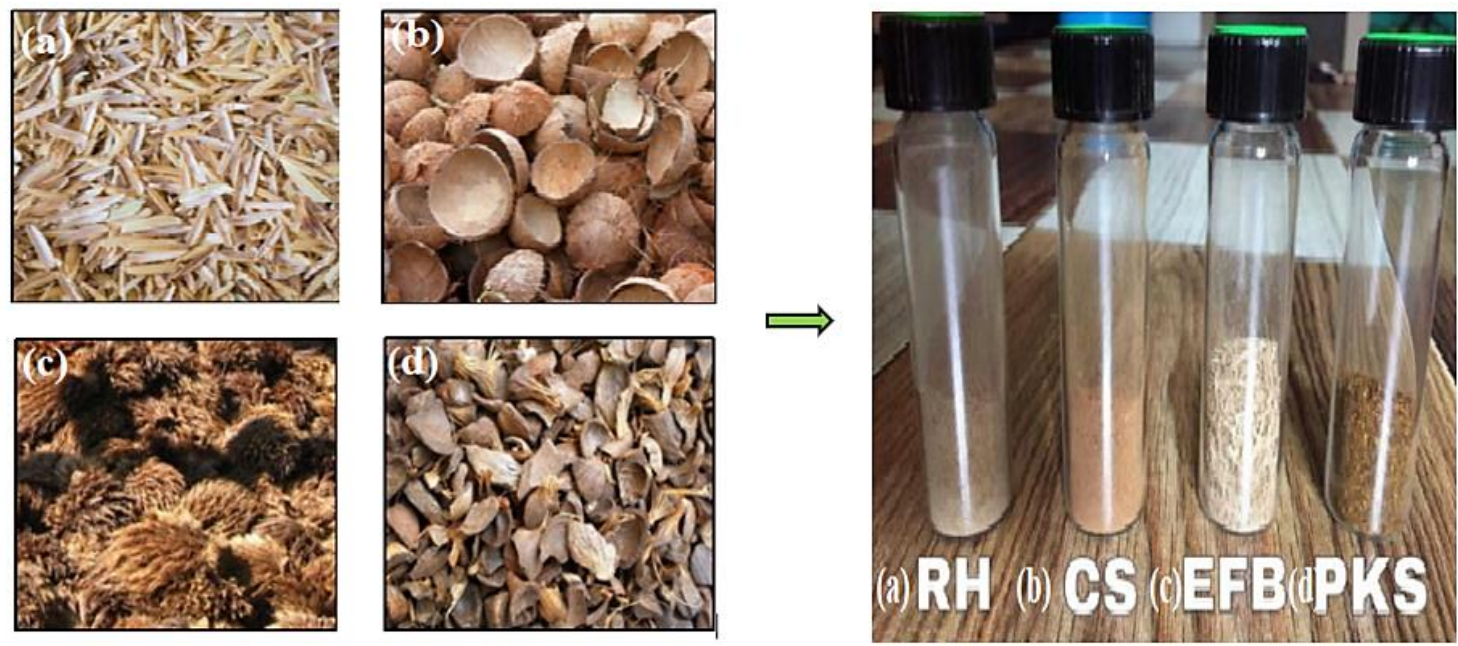

Figure 5. Unprocessed samples of: (a) RH, (b) CS, (c) EFB, and (d) PKS (on the top-left corner) and processed sample (on the top-right corner)

\section{Biomass Characterization}

Biomass characterization studies are underlying properties that cover the effective utilization in producing power. Biomass components vary from area to area that depends on where the biomass samples were obtained. Characterization of biomass such as "ultimate analysis," "proximate analysis," and the "heating value" was conducted to find the physiochemical properties of each biomass sample. An important property is the biomass elemental composition, which defines energy and conditioning the cleaner and efficient feedstocks utilizing [34]. The experiments can be conducted with standard laboratory equipment, which runs by a competent scientist or engineer.

\section{Proximate Analysis}

The "proximate analysis" on a dry basis is used to assess the "moisture content, volatile matter, ash content, and fixed carbon content" in the elemental composition in the weight percentages of the samples [35]. The proximate analysis is carried out using thermogravimetry analyzers (TGA) to analyze all of the required elemental composition, as mentioned before in all four samples, EFB, PKS, CS, and RH. The non-combustible biomass material is called ash. High ash content causes problems with fouling significantly when the ash contains a high amount of metal halides such as "potassium." Zając et al. [36] have studied biomass fuels, especially crops or residues, susceptible to high ash and potassium content," which can lead to fouling and slagging in the direct combustion boiler. Therefore, it is crucial to choose biomass with the lowest and acceptable content of ash. In previous studies by X. Wang et al. [37], this problem has been eradicated by introducing the co-firing system, whereby a specific ratio of coal and biomass was introduced to reduce the formation of silicon monoxide ( $\mathrm{SiO})$ and nitrogen monoxide $(\mathrm{NO})$.

\section{Ultimate Analysis}

The "ultimate analysis was conducted to find the weight percentages of hydrogen, carbon, nitrogen, oxygen, sulphur," and others by using the elemental analyzer, which requires costly laboratory facilities and professionally skilled analysts $[34,38]$. The performance of biomass during combustion can be predicted by using the elemental composition of a biomass sample. Biomass samples with "higher carbon and hydrogen content contribute to a higher heating value" [39]. Saidur et al. [40] discovered that fuel-bound nitrogen accounts for the majority of nitrogen oxide (NOx) emission from biomass combustion [40]. In recent discoveries by Maguyon-Detras et al. [41], fuel with lower nitrogen content would lower emissions (NOx). Most biomass materials contain sulphur of less than $0.2 \%$, with only certain biomass fuels, goes as high as $0.5 \%-0.7 \%$ [11]. During the combustion process, sulphur oxides (SOx) are produced, which are committed significantly in both acid rain production and particulate matter emissions (PM). In consideration of biomass having imperceptible sulphur content, biomass combustion insignificantly contributes to sulfur emissions [11].

\section{Higher Heating Value}

Another significant parameter contributing to the most effective method of utilizing biomass materials is the heating value that implies the energy content [38]. The heat emitted by combustion under special conditions defines the biomass energy content or heating value [19]. The enthalpy difference between reactants and products is tested using an "adiabatic bomb calorimeter," where the biomass heating value is obtained experimentally [34]. The calorific value of the feedstock from the experiment is calculated following the standard of "ISO 1928:2009. Bomb calorimetric method is used to determine "gross calorific value" and calculation of "net calorific value." The heating value of biomass implies the usable 
biomass energy "per unit mass-MJ / $\mathrm{kg}$ (BTU / lb)." The actual heat transfer power that was obtained is called "net heating value." The disparity in energy available is explained by the "chemical composition, humidity, and ash content" of the feedstock [11].

\section{RESULTS AND DISCUSSION}

As a result, from the experiment of the proximate analysis of the four biomass specimens, it has been proven that the decomposition of these biomass materials can be split into three stages; 1) starts with the desorption whereby the weight of the selected biomass material undergoes rapid initial mass loss due to moisture evaporation, 2) followed by decomposition of hemicelluloses of the sample [42], and 3) volatilization on the third stage and char combustion with lignin and cellulose decomposition subsequently by lignin degradation [42]. The initial mass loss temperature range for all four-biomass materials would be from 25 to $137^{\circ} \mathrm{C}$. Among all four tested samples from this experiment, $\mathrm{RH}$ has the lowest moisture content of (4.92\%), accompanied by PKS (5.34\%), CS (6.83\%), and EFB (8.15\%). The percentage of moisture determines the biomass material's thermochemical efficiency and the cost variation in the drying process. The lesser the moisture content, the lower the cost incurred during the drying process of the biomass.

From the experiment, it is also shown multi-step decompositions due to the stable intermediate plot, which proved that each of these selected materials has its own degradation temperature starting with (RH) $29.85^{\circ} \mathrm{C}$ and $30{ }^{\circ} \mathrm{C}$ for both (EFB) and (PKS) and $30.08^{\circ} \mathrm{C}$ for coconut shell. The degradation of the material began with the ignition temperature indicated in the graph by the denoted sign of $\mathrm{Ti}$ and follow by the multi-step decompositions or devolatilizations represented as $\mathrm{Ta}_{1}, \mathrm{Ta}_{2}$, and $\mathrm{Ta}_{3}$ and lastly with the burnout temperature indicated as $\mathrm{Tb}$ depicts from the TGA/DTG graphs of EFB, PKS, RH, and CS with the heating rate of $20{ }^{\circ} \mathrm{C} / \mathrm{min}$ in an inert medium of $\mathrm{N}_{2}$ as illustrated in Figure 6. As seen in Figure 6, it is proven that different material has different intermediate results, resulting in the multi-stage decompositions, for example, RH has only two stages, EFB and CS have three stages whereas PKS has four stages. The temperature range of particular stages was associated with the deterioration of the biomass elements, and this range was resolved to utilize the limit temperature comparing with the neighbour minimums on the DTG graph [43].
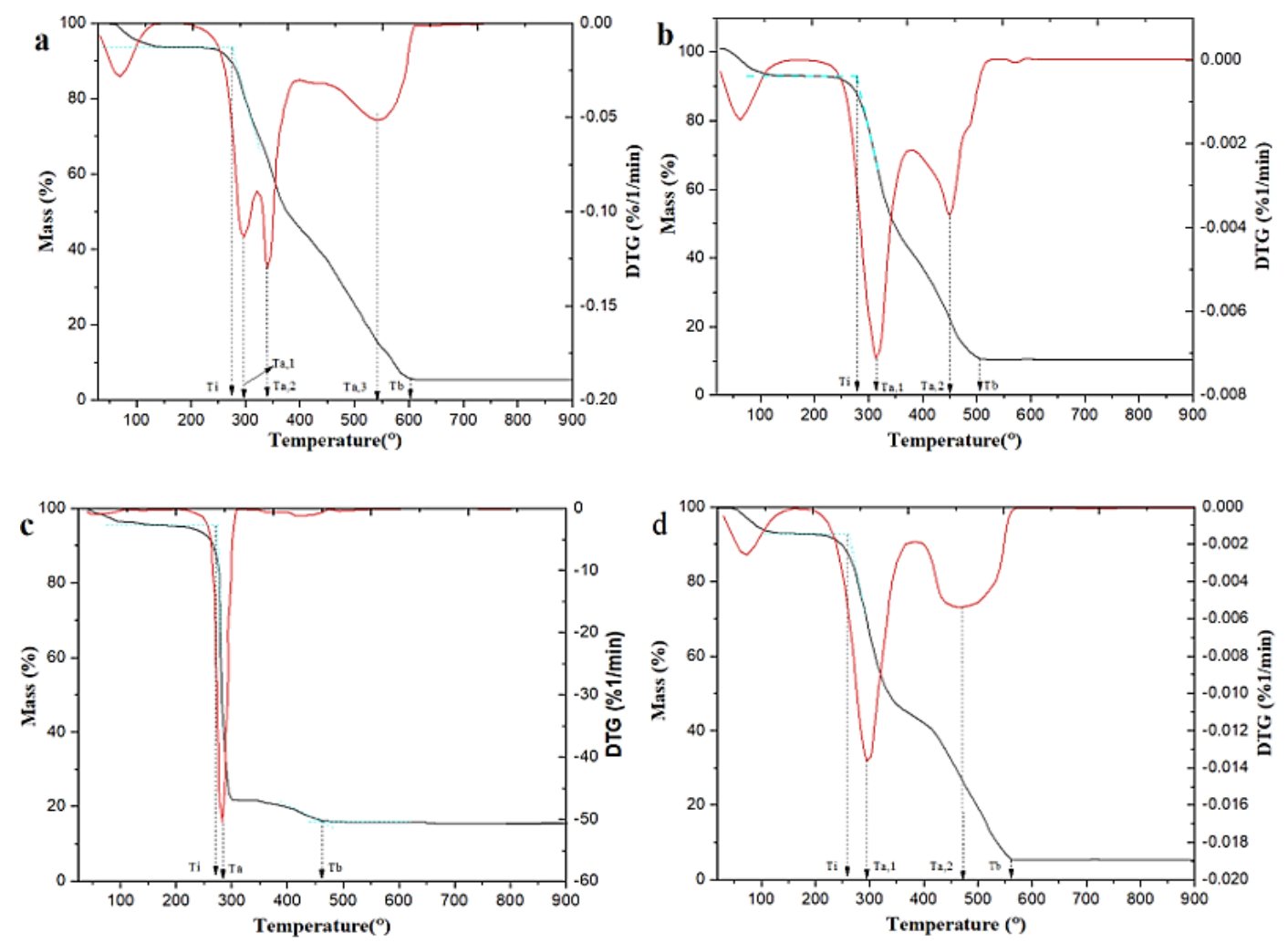

Figure 5. TGA and DTG analysis of: PKS (a), CS (b), RH (c), and EFB (d) for the heating rate of $20{ }^{\circ} \mathrm{C} / \mathrm{min}$ in an inert medium

During the decomposition of hemicelluloses and cellulose, the DTG depiction of EFB, RH, and CS display one peak temperature of $\mathrm{Ta}_{1}\left(295.0^{\circ} \mathrm{C}, 283.3^{\circ} \mathrm{C}\right.$ and $\left.313.8^{\circ} \mathrm{C}\right)$ comparing with a DTG depiction of PKS within the same vicinity temperature of $160-400{ }^{\circ} \mathrm{C}$ exhibited in two different peaks such as $\left(\mathrm{Ta}_{1}=297.1^{\circ} \mathrm{C}\right.$ and $\left.\mathrm{Ta}, 2=339.9^{\circ} \mathrm{C}\right)$ as shown in Table 2 below. Also, a proportion of lignin degraded at the temperature range of $160-400{ }^{\circ} \mathrm{C}$, depending on the experiment's biomass material [44]. Finally, the burnout temperature varies from one to another biomass due to the presence of lignin, whereby the higher the fraction of lignin, the higher the burnout temperature, which indirectly causes "higher residence 
time" and "higher temperature" needed for complete combustion in the boiler [45]. Therefore, the rate of decomposition of PKS and CS are slower, and both of these biomass materials will sustain the ignition for a more extended period and preferred as a good fuel source for thermal combustion [13] due to the high percentage of lignin as such $(50.70 \%$ and $33.30 \%)$ in comparison with EFB (22.10\%) and RH (18.0\%).

Table 2. Thermogravimetric characteristic of EFB, PKS, RH, and CS

\begin{tabular}{llllll}
\hline \multirow{2}{*}{ Biomass } & \multicolumn{5}{l}{ Characteristic } \\
\cline { 2 - 6 } & $\mathrm{T}_{\mathrm{i}}$ & $\mathrm{T}_{\mathrm{a}, 1}$ & $\mathrm{~T}_{\mathrm{a}, 2}$ & $\mathrm{~T}_{\mathrm{a}, 3}$ & $\mathrm{~T}_{\mathrm{b}}$ \\
\hline Empty fruit Bunch (EFB) & 262.4 & 295.0 & 469.4 & - & 563.8 \\
Palm kernel shell (PKS) & 275.6 & 297.1 & 339.9 & 538.9 & 611.2 \\
Rice Husk (RH) & 270.8 & 283.3 & - & - & 464.5 \\
Coconut shell (CS) & 276.9 & 313.8 & 450.7 & - & 507.3 \\
\hline
\end{tabular}

The ultimate analysis of all four-biomass materials indirectly indicates each material's thermal reactivity for combustion in the boiler. The higher the percentage of $\mathrm{C}, \mathrm{H}_{2}$, and $\mathrm{O}_{2}$, the better it is compared to a lower percentage of these three elements in any fuels. Table 3 shows that among all four-biomass material, CS has the highest carbon percentage of $(50.25 \%)$, follow by PKS (48.35\%), EFB (46.00\%), and the RH (42.50\%), whereas in hydrogen percentage; PKS has the highest value of $(6.50 \%)$ followed by EFB (6.45\%), CS (5.70\%), and the RH (5.42\%). Coconut shell has the highest oxygen percentage of $(42.57 \%)$ followed by RH $(34.61 \%)$, PKS $(34.15 \%)$, and EFB $(31.80 \%)$. The statement mentioned above significantly proved that CS ignites better than any other fuel from this study, as the higher the oxygen content, the more susceptible or easier for the combustion in the boiler to occur. Besides that, higher content of volatile matter will facilitate and sustain ignition, making the biomass more vulnerable to combustion [46]. In that sense, EFB shows the highest percentage of volatile matter (74.20\%) among the three other biomass samples from the conducted experiment.

Table 3. A proximate and ultimate analysis of HHV of EFB, PKS, RH, and CS parameters

\begin{tabular}{|c|c|c|c|c|}
\hline \multicolumn{5}{|l|}{ Parameter } \\
\hline \multicolumn{5}{|c|}{ Ultimate analysis (wt \% on a dry basis) } \\
\hline Material \& properties & $(\mathrm{EFB})$ & $(\mathrm{PKS})$ & $(\mathrm{RH})$ & $(\mathrm{CS})$ \\
\hline Carbon & 46.00 & 48.35 & 42.50 & 50.25 \\
\hline Hydrogen & 6.45 & 6.50 & 5.42 & 5.70 \\
\hline Nitrogen & 0.48 & 1.25 & 0.43 & 0.71 \\
\hline Oxygen $^{\text {a }}$ & 31.80 & 34.15 & 34.61 & 42.57 \\
\hline Sulphur & 0.10 & 0.08 & 0.01 & 0.02 \\
\hline$(\mathrm{H}: \mathrm{C})$ ratio & 0.14 & 0.13 & 0.13 & 0.11 \\
\hline$(\mathrm{O}: \mathrm{C})$ ratio & 0.69 & 0.71 & 0.81 & 0.85 \\
\hline \multicolumn{5}{|c|}{ Proximate analysis (wt \% on a dry basis) } \\
\hline Moisture & 8.15 & 5.34 & 4.92 & 6.83 \\
\hline Volatile matter & 74.20 & 71.15 & 63.20 & 71.05 \\
\hline Fixed carbon & 12.76 & 18.76 & 12.35 & 11.53 \\
\hline Ash content & 4.89 & 4.75 & 18.19 & 10.52 \\
\hline High heating value (MJ/kg) & 16.96 & 20.73 & 14.70 & 20.53 \\
\hline Hemicelluloses ${ }^{b}$ & 35.30 & 22.70 & 20.35 & 26.70 \\
\hline Cellulose ${ }^{b}$ & 38.30 & 20.80 & 33.00 & 30.58 \\
\hline Lignin $^{b}$ & 22.10 & 50.70 & 18.10 & 33.30 \\
\hline
\end{tabular}


It has been a controversial topic for more than a decade in deciding the potential of agricultural waste biomass material as a sustainable fuel source for biomass boiler due to the drawback from the excessive emission of pollutant gases such as "sulphur dioxide $\left(\mathrm{SO}_{2}\right)$, nitrogen oxides ( $\left.\mathrm{NOx}\right)$, and hydrogen chloride $(\mathrm{HCl})$ " [51]. The content of both nitrogen and sulphur has been found minuscule in this paper, with the maximum content of nitrogen exhibits in CS $(0.71 \%)$, whereas the maximum sulphur content in EFB $(0.10 \%)$. Nevertheless, both nitrogen and sulphur contents are still within the limit, further substantiating PKS, EFB, RH, and CS as a potential biomass for boiler fuel application. Besides that, excessive ash production could lead to operational problems, for example, "slagging, fouling, and corrosion" which interrupts the burning activity, diminish productivity and lead to undesirable shutdowns and elevates incomplete combustion byproducts including "carbon monoxide $(\mathrm{CO})$ and particulate matter (PM)" [51]. The lowest percentage of ash with the highest HHV would be PKS (20.73\% and 4.75\%) in all four samples, followed by CS (20.53\% and $10.52 \%)$, EFB (16.96\% and $4.89 \%)$, and the RH (14.70\% and 18.19\%). Even though EFB has a lower ash content (4.89\%) than CS (10.52\%), CS is still considered better fuel than EFB in considering other factors such as oxygen, sulphur, and moisture content.

\section{CONCLUSIONS}

Several studies have been conducted on each subject matter of individual biomass material such as EFB, PKS, RH, and CS. However, very few studies have discussed the correlation and the differences in the combustion system between these four-biomass presence from the experimental perspective. In conclusion, from the above-mentioned experimental results, it is proven that the highest lignin fraction with the highest $\mathrm{C}, \mathrm{H}, \mathrm{O}$ matters than the other minor element's presence, such as sulphur and nitrogen from the tested biomass samples of being ultimate fuel for biomass boiler application. The reduction of one element will increase another aspect from a different perspective; RH is the least favourable fuel than the other three biomass samples from the experiment. However, with the right mixing ratios of all these samples; therein, the fuel cost could be reduced, and biomass power plants could be free from the dependencies on single biomass source availability for energy production. Thus, this study's objective has been achieved by studying the feedstocks composition before using it in the biomass boiler. Nevertheless, these biomass materials can be further enhanced through pre-treatment methods such as torrefaction, pyrolysis, and densification processes to raise the energy density and increase the overall value of biomass materials.

\section{ACKNOWLEDGMENTS}

The authors would like to thank Universiti Teknologi Petronas, Seri Iskandar Perak for funding and academic advice.

\section{REFERENCES}

[1] F. Behrouzi, M. Nakisa, A. Maimun, and Y. M. Ahmed, 'Renewable energy potential in Malaysia: Hydrokinetic river/marine technology', Renew. Sustain. Energy Rev., vol. 62, pp. 1270-1281, Sep. 2016, doi: 10.1016/j.rser.2016.05.020.

[2] B. D. Altan and M. Atilgan, 'An experimental and numerical study on the improvement of the performance of Savonius wind rotor’, Energy Convers. Manag., vol. 49, no. 12, pp. 3425-3432, Dec. 2008, doi: 10.1016/j.enconman.2008.08.021.

[3] S. Bernad, A. Georgescu, S.-C. Georgescu, R. Susan-Resiga, and I. Anton, 'Flow investigations in Achard turbine', Proc. Rom. Acad. A, Rom. Acad., vol. 9, no. 2, p. 12, 2008.

[4] 'Global Bioenergy Statistics 2019 World Bioenergy Association', 2019

[5] H. J. Schellnhuber, W. Cramer, N. Nakicenovic, T. Wigley, and G. Yohe, Avoiding Dangerous Climate Change (Arctic Climate Impact Assessment), vol. 14, no. 1. 2006.

[6] R. Zevenhoven and A. Beyene, 'The relative contribution of waste heat from power plants to global warming', Energy, vol. 36, no. 6, pp. 3754-3762, Jun. 2011, doi: 10.1016/j.energy.2010.10.010.

[7] S. A. Sulaiman, M. Inayat, H. Basri, F. M. Guangul, and S. M. Atnaw, 'Effect of blending ratio on temperature profile and syngas composition of woody biomass co-gasification', J. Mech. Eng. Sci., vol. 10, no. 2, pp. 2176-2186, Sep. 2016, doi: 10.15282/jmes.10.2.2016.20.0204.

[8] R. Avtar, S. Tripathi, A. K. Aggarwal, and P. Kumar, 'Population-urbanization-energy nexus: A review', Resources, vol. 8, no. 3, pp. 1-21, 2019, doi: 10.3390/resources8030136.

[9] Eswanto and J. R. Siahaan, 'Analysis of castel type biomass combustion chamber using candlenut shell fuel for patchouli oil purifying', J. Mech. Eng. Sci., vol. 12, no. 2, pp. 3656-3670, 2018, doi: 10.15282/jmes.12.2.2018.12.0324.

[10] S. Alatzas, K. Moustakas, D. Malamis, and S. Vakalis, 'Biomass potential from agricultural waste for energetic utilization in Greece', Energies, vol. 12, no. 6, p. 20, 2019, doi: 10.3390/en12061095.

[11] K. Parmar, 'Biomass- An Overview on Composition Characteristics and Properties', IRA-International J. Appl. Sci. (ISSN 2455-4499), vol. 7, no. 1, p. 42, May 2017, doi: 10.21013/jas.v7.n1.p4.

[12] M. S. Mia, R. A. Begum, A. C. Er, R. D. Z. R. Z. Abidin, and J. J. Pereira, 'Burden of malaria at household level: A baseline review in the advent of climate change', Journal of Environmental Science and Technology, vol. 5, no. 1. pp. 1-15, 2012, doi: 10.3923/jest.2012.1.15. 
[13] N. Hamzah, K. Tokimatsu, and K. Yoshikawa, 'Solid fuel from oil palm biomass residues and municipal solid waste by hydrothermal treatment for electrical power generation in Malaysia: A review', Sustainability (Switzerland), vol. 11, no. 4. MDPI AG, pp. 1-23, 18-Feb-2019, doi: 10.3390/su11041060.

[14] B. B. Nyakuma, 'Biomass energy outlook in Malaysia using functions of innovation systems', Preprints, pp. 1-24, Feb. 2018, doi: 10.20944/PREPRINTS201802.0158.V1.

[15] Salman Zafar, 'Agricultural Biomass in Malaysia | BioEnergy Consult', Bioenergy Consult, 08-Nov-2019. [Online]. Available: https://www.bioenergyconsult.com/agricultural-biomass-in-malaysia/. [Accessed: 25-Apr-2020].

[16] W. Griffin, J. Michalek, H. Matthews, and M. Hassan, 'Availability of biomass residues for co-firing in peninsular Malaysia: Implications for cost and GHG emissions in the electricity sector’, Energies, vol. 7, no. 2, pp. 804-823, Feb. 2014, doi: 10.3390/en7020804.

[17] Nurhidayati Abd Aziz and Leon Kin Mun, 'Malaysia’s biomass potential', BiomassSP:BE-Sustainable Magazine, p. 21, Apr2012.

[18] I. A. I. Cora Bulmău,(Gheorghe), Adrian Badea, Diana Cocârţă, 'Applications of the thermochemical treatments in the sustainable development contex', Present Environ. Sustain. Dev., vol. 5, no. 1, pp. 121-130, 2011.

[19] X. Zhang and R. C. Brown, 'Introduction to thermochemical processing of biomass into fuels, chemicals, and power', in Thermochemical Processing of Biomass, 2019, pp. 1-16.

[20] S. N. Naik, V. V Goud, P. K. Rout, and A. K. Dalai, 'Production of first and second generation biofuels: A comprehensive review', Elsevier, vol. 14, pp. 578-597, 2010, doi: 10.1016/j.rser.2009.10.003.

[21] B. Saletnik, G. Zagula, M. Bajcar, M. Czernicka, and C. Puchalski, 'Biochar and Biomass ash as a soil Ameliorant: The effect on selected soil properties and yield of giant Miscanthus (Miscanthus x giganteus)', mdpi.com, vol. 11, no. 10, p. 2535, Sep. 2018, doi: 10.3390/en11102535.

[22] V. Chaloupková, T. Ivanova, O. Ekrt, A. Kabutey, and D. Herák, 'Determination of particle size and distribution through image-based macroscopic analysis of the structure of Biomass Briquettes', Energies, vol. 11, no. 2, p. 331, Feb. 2018, doi: 10.3390/en11020331.

[23] B. Patel, 'Biomass characterization and its use as solid fuel for combustion', Iran. J. Energy Environ., vol. 3, no. 2, pp. 123128, 2012, doi: 10.5829/idosi.ijee.2012.03.02.0071.

[24] S. Wang, X. Guo, K. Wang, and Z. Luo, 'Influence of the interaction of components on the pyrolysis behavior of biomass', $J$. Anal. Appl. Pyrolysis, vol. 91, no. 1, pp. 183-189, 2011, doi: 10.1016/j.jaap.2011.02.006.

[25] B. C. L. Fui, 'Studies of syngas cleaning technologies suitable for power generation from Biomass oil palm shells', Curtin University, 2011.

[26] V. Pasangulapati, 'Devolatilization characteristics of cellulose, hemicellulose, lignin, and the selected biomass during thermochemical gasification: Experiment and modeling studies', Oklahoma State University, 2012.

[27] D. Mohan, C. U. Pittman, and P. H. Steele, 'Pyrolysis of wood/biomass for bio-oil: A critical review', Energy and Fuels, vol. 20, no. 3, pp. 848-889, May 2006, doi: 10.1021/ef0502397.

[28] M. Balat, M. Balat, E. Kirtay, and H. Balat, 'Main routes for the thermo-conversion of biomass into fuels and chemicals. Part 2: Gasification systems', Energy Convers. Manag., vol. 50, no. 12, pp. 3158-3168, Dec. 2009, doi: 10.1016/j.enconman.2009.08.013.

[29] P. Fatehi, 'Production of biofuels from cellulose of woody biomass', in Cellulose - Biomass Conversion, InTech, 2013, pp. 4674.

[30] R. C. Brown, 'Introduction to thermochemical processing of biomass into fuels, chemicals, and power', in Thermochemical Processing of Biomass: Conversion into Fuels, Chemicals and Power, 2011, pp. 1-12, doi: 10.1002/9781119990840.ch1.

[31] D. Tarasov, M. Leitch, and P. Fatehi, 'Lignin-carbohydrate complexes: Properties, applications, analyses, and methods of extraction: A review', Biotechnology for Biofuels, vol. 11, no. 1. BioMed Central Ltd., 29-Sep-2018, doi: 10.1186/s13068-018$1262-1$.

[32] F. X. Collard and J. Blin, 'A review on pyrolysis of biomass constituents: Mechanisms and composition of the products obtained from the conversion of cellulose, hemicelluloses and lignin', Renewable and Sustainable Energy Reviews, vol. 38. Elsevier Ltd, pp. 594-608, 2014, doi: 10.1016/j.rser.2014.06.013.

[33] M. Balat, 'Production of bioethanol from lignocellulosic materials via the biochemical pathway: A review', Energy Convers. Manag., vol. 52, no. 2, pp. 858-875, Feb. 2011, doi: 10.1016/j.enconman.2010.08.013.

[34] G. Montero et al., 'Higher heating value determination of wheat straw from Baja California, Mexico', Energy, vol. 109, pp. 612-619, Aug. 2016, doi: 10.1016/j.energy.2016.05.011.

[35] J. Parikh, S. A. Channiwala, and G. K. Ghosal, 'A correlation for calculating elemental composition from proximate analysis of biomass materials', Fuel, vol. 86, no. 12-13, pp. 1710-1719, Aug. 2007, doi: 10.1016/j.fuel.2006.12.029.

[36] G. Zając, J. Szyszlak-Bargłowicz, W. Gołębiowski, and M. Szczepanik, 'Chemical characteristics of biomass ashes', Energies, vol. 11, no. 11, pp. 1-15, 2018, doi: 10.3390/en11112885.

[37] X. Wang et al., 'Experimental investigation on biomass co-firing in a $300 \mathrm{MW}$ pulverized coal-fired utility furnace in China', Proc. Combust. Inst., vol. 33, no. 2, pp. 2725-2733, 2011, doi: 10.1016/j.proci.2010.06.055.

[38] S. Hosseinpour, M. Aghbashlo, M. Tabatabaei, and M. Mehrpooya, 'Estimation of biomass higher heating value (HHV) based on the proximate analysis by using iterative neural network-adapted partial least squares (INNPLS)', Energy, vol. 138, pp. 473-479, 2017, doi: 10.1016/j.energy.2017.07.075. 
[39] M. Z. Stummann et al., 'Deactivation of a CoMo catalyst during Catalytic Hydropyrolysis of biomass. Part 1. Product distribution and composition', Energy and Fuels, vol. 33, no. 12, pp. 12374-12386, Dec. 2019, doi: 10.1021/acs.energyfuels.9b02523.

[40] R. Saidur, E. A. Abdelaziz, A. Demirbas, M. S. Hossain, and S. Mekhilef, 'A review on biomass as a fuel for boilers', Renewable and Sustainable Energy Reviews, vol. 15, no. 5. pp. 2262-2289, Jun-2011, doi: 10.1016/j.rser.2011.02.015.

[41] M. C. Maguyon-Detras, M. V. P. Migo, N. Van Hung, and M. Gummert, 'Thermochemical conversion of rice straw', in Sustainable Rice Straw Management, Springer International Publishing, 2020, pp. 43-64.

[42] M. V. Gil, D. Casal, C. Pevida, J. J. Pis, and F. Rubiera, 'Thermal behaviour and kinetics of coal/biomass blends during cocombustion’, Bioresour. Technol., vol. 101, no. 14, pp. 5601-5608, Jul. 2010, doi: 10.1016/j.biortech.2010.02.008.

[43] M. Varol, A. T. Atimtay, B. Bay, and H. Olgun, 'Investigation of co-combustion characteristics of low quality lignite coals and biomass with thermogravimetric analysis', Thermochim. Acta, vol. 510, no. 1-2, pp. 195-201, Oct. 2010, doi: 10.1016/j.tca.2010.07.014.

[44] M. Poletto, 'Assessment of the thermal behavior of lignins from softwood and hardwood species', Maderas Cienc. y Tecnol., vol. 19, no. 1, pp. 63-74, 2017, doi: 10.4067/S0718-221X2017005000006.

[45] J. W. Cumming and J. McLaughlin, 'The thermogravimetric behaviour of coal', Thermochim. Acta, vol. 57, no. 3, pp. 253272, Sep. 1982, doi: 10.1016/0040-6031(82)80037-3.

[46] Q. Yi et al., 'Thermogravimetric analysis of co-combustion of biomass and biochar', J. Therm. Anal. Calorim., vol. 112, no. 3, pp. 1475-1479, Jun. 2013, doi: 10.1007/s10973-012-2744-1.

[47] S. H. Kong, S. K. Loh, R. T. Bachmann, S. A. Rahim, and J. Salimon, 'Biochar from oil palm biomass: A review of its potential and challenges', Renewable and Sustainable Energy Reviews, vol. 39. Elsevier Ltd, pp. 729-739, 01-Nov-2014, doi: 10.1016/j.rser.2014.07.107.

[48] S. Palamae, P. Dechatiwongse, W. Choorit, Y. Chisti, and P. Prasertsan, 'Cellulose and hemicellulose recovery from oil palm empty fruit bunch (EFB) fibers and production of sugars from the fibers', Carbohydr. Polym., vol. 155, pp. 491-497, Jan. 2017, doi: 10.1016/j.carbpol.2016.09.004.

[49] E. C. Okoroigwe, C. M. Saffron, and P. D. Kamdem, 'Characterization of palm kernel shell for materials reinforcement and water treatment', vol. 5, no. 1, pp. 1-6, 2014, doi: 10.5897/JCEMS2014.0172.

[50] N. Arena, J. Lee, and R. Clift, 'Life Cycle Assessment of activated carbon production from coconut shells', J. Clean. Prod., vol. 125, pp. 68-77, Jul. 2016, doi: 10.1016/j.jclepro.2016.03.073.

[51] T. Nussbaumer, 'Combustion and co-combustion of biomass: Fundamentals, technologies, and primary measures for emission reduction †’, ACS Publ., vol. 17, no. 6, pp. 1510-1521, Nov. 2003, doi: 10.1021/ef030031q. 